\title{
Testing Mate Choice Hypotheses in a Transitional Small Scale Population
}

\section{Lynda G. Boothroyd, et al. [full author details at the end of the article]}

Received: 12 June 2020 / Revised: 6 August 2021 / Accepted: 9 August 2021 /

Published online: 3 September 2021

(C) The Author(s) 2021

\begin{abstract}
Objective Tests of theories of mate choice often rely on data gathered in White, industrialised samples and this is especially the case for studies of facial attraction. Our understanding of preferences for sexual dimorphism is currently in flux and a number of hypotheses require testing in more diverse participant samples. The current study uses opportunistically gathered facial dimorphism preference data from 271 participants in rural Nicaragua, and 40 from the national capital Managua. We assess pre-registered hypotheses drawn from sexual selection theory, and from more recent approaches which consider the impacts of economic development and cultural 'modernisation' on mate preferences.

Methods Participants verbally reported demographic data, and indicated preferences for five male and five female pairs of faces manipulated to differ in sexually dimorphic facial structure based on a sample of Salvadoran individuals.

Results While urban participants showed a preference for more feminine female faces, this preference was not evident in the rural participants. Neither urban nor rural participants showed any directional preference for masculinised/feminised male faces. Furthermore, there was no support for any other pre-registered hypothesis.

Conclusions Our results are consistent with previous studies showing no interest in facial dimorphism in less globally-acculturated, or market integrated, populations. Together, this suggests that while facial dimorphism may be subject to systematically varying preferences amongst some low-fertility, industrialised populations, it is not a feature which is likely to have been important in ancestral populations. We call for further work attempting to replicate well known mate choice phenomena in more diverse samples.
\end{abstract}

Keywords Masculinity · Femininity · Dimorphism · Facial attraction · Hispanic · Miskitu $\cdot$ Garifuna $\cdot$ Mestizo $\cdot$ Creole 


\section{Introduction}

Facial masculinity and femininity preferences have been a prominent focus of research in interpersonal attraction and sexual selection since the late 1990s (e.g., Perrett et al., 1998; Thornhill \& Gangestad, 1999). This literature was sparked by the hypothesis that since humans display mutual mate choice, we should see preferences for secondary sexual characteristics in potential mates which mirror those in non-human species. That is, choosers should prefer stronger sex-typical cues in their potential mates and these choices should indeed function as the means by which these traits evolved (see for instance, plumage preferences in birds, and colour preferences in sticklebacks).

While an early consensus emerged that men (and women) preferred female faces which showed exaggerated feminine traits (e.g., Perrett et al., 1998; Feinberg et al., 2005), preferences for masculinity in male faces proved more ambiguous (e.g., Perrett et al., 1998; Rhodes et al., 2000). Some studies found that participants preferred male faces which were more 'masculine' than average (typically in terms of the measurable shape differences between male and female faces, or sometimes faces rated by observers as more masculine), but other studies found preferences for less masculine/more androgynous male faces. Furthermore, much of the literature suggested there was systematic variation between- and within-women in terms of the degree of masculinity they preferred in male faces. Generally these studies showed a tendency for women to prefer masculine features to a greater degree when they were in a relationship (Penton-Voak et al., 1999), when they were sociosexually unrestricted (Waynforth et al., 2005), when they were explicitly selecting a short term partner (Little et al., 2002), and when they were most likely to become pregnant (Penton-Voak et al., 1999).

Consistent preferences for femininity in female faces were interpreted as evidence that facial femininity is a valid indicator of fertility via oestrogen (Law Smith et al., 2005). As such, men seeking a female partner should be drawn primarily to more feminine features. The observed variations in women's preferences, on the other hand, were interpreted in terms of a trade-off women made between high genetic quality (indicated by masculinity, as a proxy for testosterone and underlying quality), and suitability as a long term partner (which, it was argued, was hindered by elevated testosterone). Men with more masculine faces are perceived as, and selfreport being, more interested in short term sexual relationships (e.g. Boothroyd et al., 2008, 2011), and may be more physically aggressive and show stronger responses to male-male competition (e.g., Dabbs et al., 1991).

Two key problems have arisen with these understandings of femininity and masculinity preferences, however. Firstly, the biological bases of femininity and masculinity and their links to the supposed selection benefits they confer have come under question. Recent research using large samples and often pre-registered analyses has cast doubt on the claim that more facially feminine women have higher endogenous oestrogen (Jones et al., 2018b). Similarly the precise relationship between masculinity in men and testosterone remains contested (e.g. Kordsmeyer et al., 2019) and the supposed link between facial masculinity in men 
and heritable health appears dubious. For instance, more masculine men do not appear to have more viable offspring (Boothroyd et al., 2017), do not have better self-reported future health (Boothroyd et al., 2013), and do not have genotypes conferring broader pathogen immunity (Zaidi et al., 2019). Furthermore, a series of studies in 2018 showed no evidence for an effect of female fertility on preferences for masculinity, overturning nearly two decades of published evidence (e.g., Jones et al., 2018a; Marcinkowska et al., 2018, Junger et al., 2018).

The second key problem is that the literature discussed above was based on studies carried out almost exclusively in industrialised and usually White-majority countries, meaning they may not offer a comprehensive understanding of human mate preferences on this topic. While an earlier cross-cultural study found no difference between Japanese and UK samples (Perrett et al., 1998), later studies found that non-Western samples preferred more masculine male faces (Penton Voak et al., 2004: Jamaica; Scott et al., 2008: Indonesia). Large scale cross-cultural studies have also yielded a range of contradictory outcomes. DeBruine et al. (2010), found that internet samples in 30 countries had stronger preferences for masculinity in nations with poorer health indices (supposedly supporting the link between masculinity and heritable health, although cf. Brooks et al., 2010) and similar results were found for preferences for faces of men with higher testosterone (Moore et al., 2013). However, a more recent online study using superior statistical analysis (mixed models with individual participant variance retained) found that masculinity preferences were stronger in countries with better health indices, higher development indices, and more unrestricted sociosexuality (Marcinkowska et al., 2019). Only one study to date has compared a number of smallscale societies with industrialised nations. Scott et al. (2014) found that better health outcomes predicted stronger masculinity preferences, and also that the best predictor of increased preference strength was higher population density. They therefore suggested that masculinity preferences were evolutionarily novel, and derived from the effects of urbanisation on opportunities to observe physiological and behavioural correlations; for instance, individuals in urbanised populations might more easily notice and internalise a tendency for more masculine men to be more aggressive.

Given these overall differences between culturally divergent samples, and the weakening theoretical basis for the proposed evolutionary drivers of dimorphism preferences, it becomes all the more important that hypotheses regarding variation in mate preferences previously developed and tested in industrialised nations are also investigated in small scale societies and other non-Western, low- and middleincome populations. This inevitably requires in-person testing of particular populations which cannot be accessed through methods frequently used for cross-cultural comparisons above, and focuses on groups at the sub-national level. For instance, Batres \& Perrett (2014) found that rural Salvadorans with no internet access showed significantly weaker masculinity preferences in male faces (and weaker femininity preferences in female faces) than urbanised participants with internet access, suggesting that online samples may provide a distorted perspective of the populations in low- and middle-income countries. Furthermore, testing samples not usually considered in the attraction literature can give rise to new hypotheses. For instance, 
Borras-Guevara et al. (2017) found that exposure to community violence led to weaker masculinity preferences in Colombian women.

The current study investigates the facial masculinity and femininity preferences of an ethnically diverse sample of rural Nicaraguans living in the Pearl Lagoon Basin region on the country's southern Caribbean coast. Our participants were almost all drawn from 4 ethnic groups: the Spanish-speaking Mestizos are of mixed European and indigenous descent, and are the dominant ethnic group within Nicaragua as a whole although relatively newer to the Caribbean coast; the Miskitu are an indigenous ethnolinguistic group which populates the Caribbean coasts of Nicaragua and Honduras; the Garifuna are an ethnolinguistic group of African and Black Carib descent found along the Caribbean coast from Belize to Nicaragua, while Creoles are Creole English speaking descendants of predominantly British and Black African/Caribbean descent. At the time of data collection, the communities studied met the definition of 'small scale' societies in many respects: they live in broadly egalitarian villages (the Pearl Lagoon communities hold land in common and each village has elected community leaders who interface between the community and the representatives of the regional government), subsist predominantly on small-scale farming and/or fishing with low levels of employment outside the communities, and are strongly oriented around personal relationships in their social structure. However, the communities were also on the cusp of rapid development. The government has been increasing infrastructural support to some of these communities across the last decade (e.g. roads to the region, electricity and mains water to the villages) and eco-tourism provided a new income stream alongside occasional income from fortuitous drug hauls and cruise-ship work (Jamieson 2018). There is thus increasing economic stratification in the coastal areas. Furthermore, opportunities for high school attendance and university education are improving in the region, meaning that young community members are increasingly looking outside the communities for their futures. Finally, a growing number of villagers have mobile phones and sometimes broadband signal which is increasing their external connectivity (there was almost no smart phone usage at the time of data collection, although signal is now increasingly strong across the communities).

We began data collection in these villages in order to document the impacts of this development (specifically increasing television access) on body weight preferences (Boothroyd et al., 2016, 2020, Jucker et al., 2017; see also Thornborrow et al., 2018, 2020). However, facial masculinity/femininity preferences were also opportunistically tested in five villages $(N=271)$, and a comparator urbanised sample in Managua $(N=40)$, with a view to conducting exploratory analyses on whether television access/consumption also affected facial preferences. Alongside this, demographic data were gathered from all participants in order to appropriately characterise our sample in resulting publications. As a result, we have a dataset which not only includes television consumption and facial preferences, but also includes variables which would allow us to test other hypotheses derived from the current mate choice literature. Specifically, we have television access and consumption, age, partnership and parental status, number of offspring, and income and education. We also have approximate or precise population size of each community. In the following paragraphs, we outline the key hypotheses we will be testing with these data. 
Hypotheses 1 to 3 derive from sexual selection theory and pre-suppose an association between masculinity and some form of indirect benefits, while Hypotheses 4 to 6 draw on more recent arguments relating to the importance of cultural and economic predictors of attraction.

\section{Sexual Selection Predictions}

\section{Group Level Effects: Mating Systems}

Creole, Garifuna and Miskitu ethnic groups in the region are historically matrilocal and remain broadly matrifocal (though see Jamieson, 2018). Relationships in the communities we observed were typically characterised by serial monogamy and extra-pair matings were considered normative although not desirable. Children typically resided with their mother (although they may also move between the homes of close relatives) and in our current sample women tended to report more children than men (see Supplementary output, section 4), in keeping with the possibility that men may not always know of or acknowledge all their offspring. In contrast, Mestizo residents of the region were more strictly monogamous, were likely to reside in nuclear families, and were more patriarchal (for instance, wives sometimes required permission from their husbands to interact with us). As such Mestizo communities had a more restricted sociosexuality norm than other groups. As discussed above, it has been argued that women with more restricted sociosexuality, or who are choosing a long-term partner (and not a potential short term and/or extra-pair partner), should select a less masculine face than those more open to short term partners either because they are less concerned with 'good genes' or because they are more concerned with cues to good partnership traits (Rhodes et al., 2003; Booth, \& Dabbs, 1993). A sexual selection perspective would therefore predict that:

H1: Mestizo women will show preferences for more feminine male faces than women in other ethnic groups. (Rural sample only)

\section{Individual Effects: Age}

Mate preferences seem to emerge across childhood and puberty and may decline across menopause (see Boothroyd \& Vukovic, 2019, for review). With specific reference to facial dimorphism, Little et al., (2010) found that masculinity preferences were stronger in 14- than in 11-year old girls, and were also stronger in pre- than post-menopausal women. Similarly, Vukovic et al. (2008) and Jones et al. (2011) found that masculinity preferences were weaker in post-menopausal or older women. In contrast, however, we note that Saxton et al. (2011) and Boothroyd et al. (2014) found that preferences for facial femininity (in male and female faces) became stronger in all children between c. 14 and 17 years of age. Previous research (Boothroyd et al., 2009) had established that most participants preferred the feminised versions of Boothroyd et al's stimuli - implying that for these stimuli, it is likely that the feminised versions were seen as 'higher value'. We therefore make a clear 
hypothesis regarding women's masculinity preferences from a sexual selection perspective, and will run additional exploratory models testing for general associations between age and dimorphism in both sexes of face.

$\mathrm{H} 2$ : There will be a curvilinear relationship between age and dimorphism preferences in women, with those preferences being weaker in the youngest and oldest participants.

(We note for $\mathrm{H} 2$ that the number of participants under 18 is relatively small and as such the older age group may be more critical in testing this hypothesis. Analyses will also consider categorical age groups.)

\section{Individual Level Effects: Partnership Status}

Previous cross-sectional studies have found that women who are in committed relationships prefer more masculinised male faces than other women (Little et al., 2002, though cf. e.g. Holzleitner \& Perrett, 2017), potentially because they are instinctively treating the stimuli as potential extra-pair partners rather than as potential new long-term partners. We therefore make the following hypothesis:

H3: Women in co-habiting relationships will prefer more masculine faces than women in casual relationships, or those who are single.

A secondary model will assess the same hypothesis controlling for ethnicity if H1 is supported. We will also conduct exploratory analyses on male relationship status and femininity preferences.

\section{Economic Development Predictions}

\section{Group Level Effects: Population Density and Development}

As discussed above, two studies have now suggested that masculinity preferences may be relatively evolutionarily novel and associated with more developed and/or urbanised environments (Marcinkowska et al., 2014; Scott et al., 2014). We would therefore predict that fully urbanised participants in Managua would have stronger dimorphism preferences than those in rural locations and that the villages which are denser and have more infrastructure in the rural sample would have stronger dimorphism preferences than those in smaller or less 'developed' villages.

We gathered facial preferences data in 5 villages: two Mestizo-majority communities (S1 and S2), two Miskitu-majority (M1 and M2) and one Garifunamajority community with a Mestizo minority (C1). For the purposes of our research, the villages can be approximately ordered by density and development. Specifically: S2 is a larger community (c. 2400 people) with a comparatively densely populated central area, shops, established electricity and mains water, and a high school. Many houses are built of concrete. M2 is a smaller community 
of c. 740 individuals but is more densely built than our other villages (except S2) with an increasing number of concrete houses; it has a high school, a meeting house and two beach side bars, and had mains electricity by the time of data collection. Most residents had relatively easy access via their own or a friend's boat to Pearl Lagoon town for shops. S1 consists of c. 2000 people but spread across a wide area of loosely associated homesteads, with no village centre or shops, and only elementary education. Most houses were small wooden 'board houses'. It had no mains electricity or water at the time of data collection, although a small number of families had solar panels. M1 has 1123 residents and is similar to S1, but with only one solar panel in the village, belonging to the community leader. Finally $\mathrm{C} 1$ is a very small community of roughly 50 adults and their children. At the time of data collection, there was no source of electricity and residents all lived in small board houses with leaf or corrugated iron rooves.

H4: All dimorphism preferences (masculinity in men and femininity in women) will be stronger in denser and more 'developed' communities.

\section{Individual Level Effects: Socioeconomic Status}

Socioeconomic status may influence preferences through both sexual selection and culturally based routes. Previous research has suggested that individual socioeconomic status may influence mate preferences. For instance, Moore et al. (2006, 2010) found that women with greater resource control had greater preferences for physical attractiveness relative to resources in a partner, perhaps because their economic stability meant they were less reliant on financial investment from a partner. As such, in our sample, whichever of our stimuli are more valued in general (masculinised or feminised male faces), more educated women with more financial opportunities, may show that preference more strongly. Similarly, it has been argued from a sexual selection perspective that men with greater levels of resources may 'trade' these for more attractive female partners (e.g. Buss, 1988). This may be particularly the case in a setting such as ours where the population is generally of low SES, so those with more income and/or education may have a clearly visible advantage. Furthermore, attending a high school or university in this region often requires travel to the larger communities or the regional capital. As such, we would expect a general effect of education on exposure to media imagery in both sexes (see below). We would therefore predict:

H5a: Individuals with higher income or education will prefer more feminised female faces. (Note, under sexual selection this would be particularly the case for opposite sex faces; under an indirect exposure effect, education should have more impact than income.)

$\mathrm{H} 5 \mathrm{~b}$ : Women with higher income and education will show more exaggerated preferences for men with the more valued level of dimorphism. (Note, if there is no overall directional preference for dimorphism in male faces, then the models associated with this hypothesis become exploratory.) 


\section{Individual Level Effects: Television Consumption}

Our previous research, cited above, found that television viewing, is likely affecting body preferences in this population. Furthermore, as discussed above, Batres \& Perrett (2014) found that access to another source of visual media (the internet) predicted stronger dimorphism preferences for both sexes of face in a sample of Latin American men and women. Our participants reported preferring to watch action movies (called Van Dammes or fighting pictures) and telenovelas (Latin American soaps), both of which typically feature more muscular and facially rugged men and more feminised women than the typical population. We therefore predict:

H6 Those who watch more television will prefer more feminised female faces, and more masculinised male faces. (Initial analyses already run in original rural population.)

\section{Methods}

\section{Participants}

Three hundred and eleven participants were recruited from five villages in the Pearl Lagoon Basin of Nicaragua, and from the national capital Managua. Two villages were predominantly Miskitu, two were predominantly Mestizo, and one was predominantly Garifuna with a large Mestizo minority. Half of participants were men and half were women. We aimed to recruit 40 participants $(20 \mathrm{~m})$ per community, although in one community we tested every available adult (where adult was defined by the local community, so included teenagers). In another community, an additional 24 participants were tested as part of another project. In two communities we also tested 47 additional participants two years after initial data collection as part of a related ongoing study. Participants in Managua were recruited from a relatively low SES neighbourhood. Sample demographic characteristics are given in Table 1 and

Table 1 Summary of each continuous variable

\begin{tabular}{|c|c|c|c|c|c|c|c|c|c|}
\hline & $\mathrm{n}$ & mean & SD & median & $\min$ & $\max$ & skew & kurtosis & SE \\
\hline Age & 311 & 27.74 & 11.57 & 24 & 14 & 77 & 63 & 1.37 & 1.76 \\
\hline Years of marriage & 90 & 10.41 & 12.22 & 6 & 0 & 60 & 60 & 1.65 & 2.48 \\
\hline \# children & 208 & 3.14 & 2.74 & 2 & 0 & 16 & 16 & 1.66 & 3.36 \\
\hline Earnings last year (\$) & 311 & 745.29 & 2362.50 & 117.65 & 0 & 36,000 & 36,000 & 11.34 & 159.09 \\
\hline Years of education & 311 & 6.72 & 4.66 & 7 & 0 & 20 & 20 & 0.07 & -0.89 \\
\hline Hours TV last 7 days & 311 & 8.90 & 10.28 & 5 & 0 & 56 & 56 & 1.42 & 2.24 \\
\hline Acculturation & 226 & 2.80 & 1.03 & 3.25 & 1.08 & 4.17 & 3.08 & -0.14 & -1.78 \\
\hline \multicolumn{10}{|l|}{ Masculinity preferences } \\
\hline - male faces & 300 & 0.43 & 0.26 & 0.40 & 0 & 1 & 0.18 & -0.70 & 0.01 \\
\hline - female faces & 300 & 0.48 & 0.25 & 0.40 & 0 & 1 & 0.02 & -0.63 & 0.01 \\
\hline
\end{tabular}


Fig. 1 below. For more detail on the region and communities, see Boothroyd et al. (2020).

\section{Questionnaire}

Participants completed a verbal questionnaire in which they reported demographic information (age, sex, ethnicity, partner ethnicity, marital and parental status); their highest level, and total years of, education; their earnings in the last year in Nicaraguan Cordobas or US Dollars (for analysis, all earnings were converted into US Dollars at $28 \mathrm{NIC} / \$$ ); whether they had access to television (in their own home or in a friend's home they visit) and how many hours of television they had watched in the last 7 days. They then verbally completed an adapted version of the Self-Identity Acculturation Scale (Cuellar et al., 1980; Suinn et al., 1987) which assessed their relative use of/social connection to an acculturated language category (US English and Spanish) vs an un-acculturated category (Miskitu and Creole English). However, acculturation was strongly bimodal and effectively proxied Mestizo ethnicity, with non-Mestizo participants all scoring at the lower-end of the scale, so was not analysed further.

\section{Facial Preference Task}

Participants viewed pairs of faces manipulated on dimorphism, which were created using photographs collected of Salvadoran Mestizos by Batres et al., (2017). Five composite faces of each sex (made by averaging 3 faces together) were masculinised by adding $50 \%$ of the shape differences between a male prototype ( $N=38$ faces $)$ and a female prototype ( $N=43$ faces). These same faces were feminised by subtracting those shape differences. Participants thus viewed 10 pairs of faces in all. Participants viewed all dimorphism stimuli and facial ethnicity stimuli for another study in a randomised order on a laptop, and were asked to indicate which face within each pair they found most attractive (Creole: 'better, more attractive, more good looking'; Spanish: mas atractivo). Preferences were calculated as the proportion of trials in which participants selected the masculinised face.

\section{Statistical Power}

With 270 rural participants, we have good power for detecting medium to large effects seen in some previous related studies to our own. For instance, Little et al. (2002) found relationship status effects on preferences with $d=.56$ (amongst noncontracepting women), which is detectable with $95 \%$ power with 140 participants. Regarding age effects, Little et al. (2010 Study 3) had a much larger sample than our own, but found that the difference in preferences between women aged 35-45 and over 45 showed an effect size of 1.3 which could be detected with $80 \%$ power with only 9 participants per group. On the other hand, associations between sociosexuality and masculinity preferences may be weaker; Boothroyd \& Brewer (2014) observed a correlation of .22 with 124 women but reliably detecting an association 


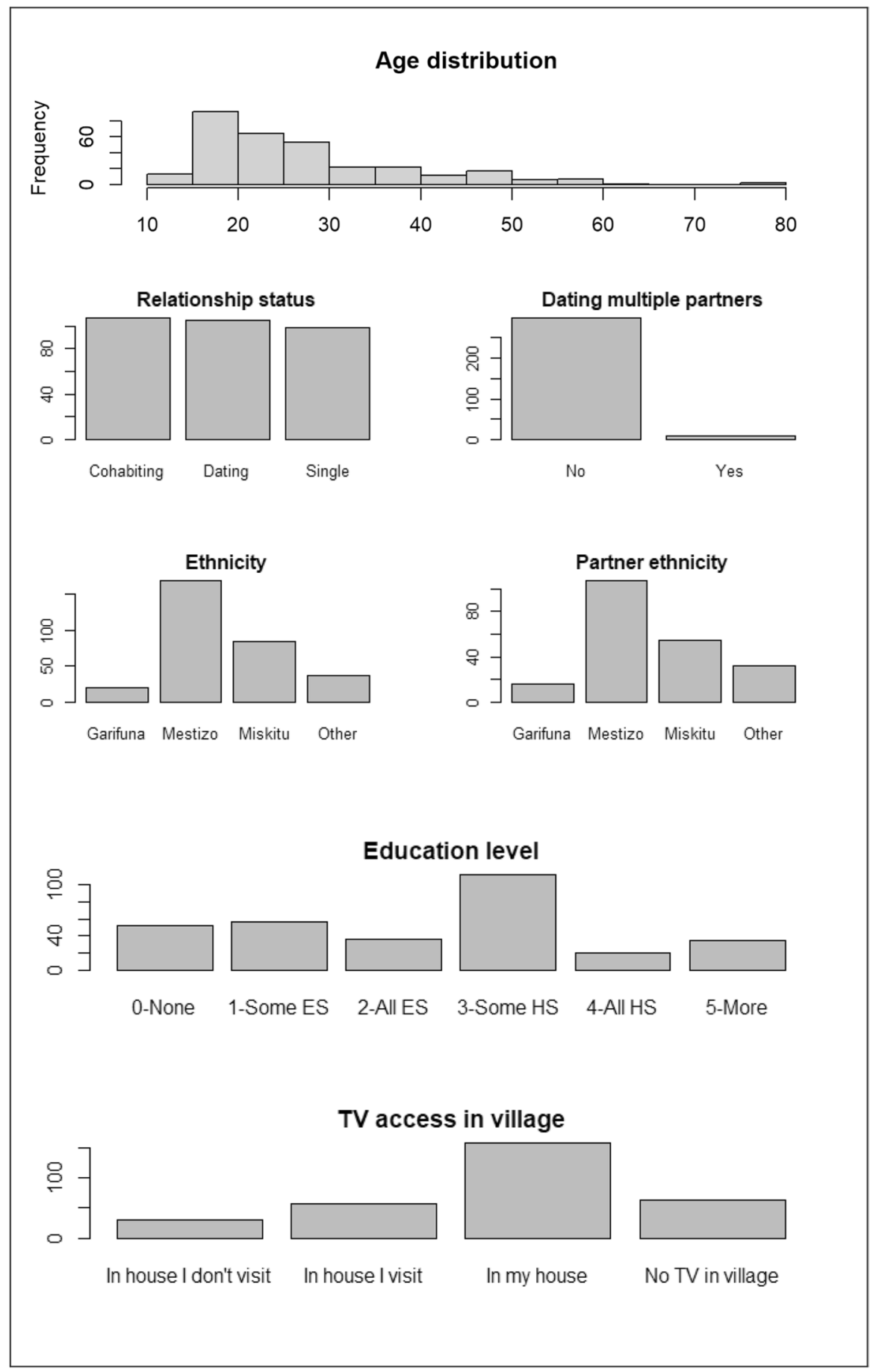

Fig. 1 Summary of age and categorical demographic variables for the full sample. (ES=elementary schools, HS = high school) 
of that size with $95 \%$ power would require 215 participants. We may therefore be underpowered for some of our predictions within one gender.

\section{Data Access and Analyses}

At the point of Stage 1 submission of this manuscript, demographic variables (age, income, education, TV consumption, acculturation) for the first 264 participants had been analysed to give means for each community and to give overall relationship status and parity in other publications. Age, income, education, TV consumption, hunger and acculturation had been used in linear analyses with an alternative outcome (body size preference and facial ethnicity preference). Linear models testing the association between TV consumption and masculinity preference had also been run in part of the sample (see below). The lead author ran exploratory correlations on a subsample of the data in 2016, including facial masculinity preferences; however she had no memory of the outcomes and had not accessed the relevant files since. None of the other planned analyses had been run with any section of the data, and the authors have not accessed the data file while formulating the hypotheses above and planning these analyses. Analysis code was prepared using simulated data. Stage 1 registration can be found here https://psyarxiv.com/456wg/ (see Version 1).

Data were analysed in $R$ 4.0.3 (R Core Team, 2020) using RStudio 1.3 (R Studio Team, 2020). All continuous predictor variables were initially tested for association with facial preferences using Pearson's correlation analyses in apaTables 2.0.8 (Stanley, 2021). Overall masculinity and femininity preferences were compared with other overall sample preferences (based on published means and SD). Remaining analyses were run with linear regression and mixed effect models using lme4 1.1-26 (Bates et al., 2015) where village was a level 2 random effect (unless village was a fixed effect, as in the analyses on community development). Age was included as a linear covariate in all models where it was not a primary predictor as age profiles differed somewhat across communities tested. Specific models planned to test hypotheses are given in supplementary Table S1. Linear model output was compiled for publication using the tab_model function of SjPlot 2.8.6 (Lüdecke, 2020) and figures were produced using ggplot2 3.3.3 (Whickham, 2016). All analysis code and RMarkdown 2.4 (Allaire et al., 2020) output are included in the supplementary materials; note that we include redacted and simulated data but not full original data due to risks of re-identification in small communities.

\section{Results}

Overall means for all measures are shown in Table 1. We also show facial masculinity preferences in our own study and other samples from Latin America using similar methods, in Table 2 and Fig. 2 below. Our values for male faces are within the general range of other studies which have found observers to sometimes prefer masculinised male faces, sometimes feminised male faces, and 


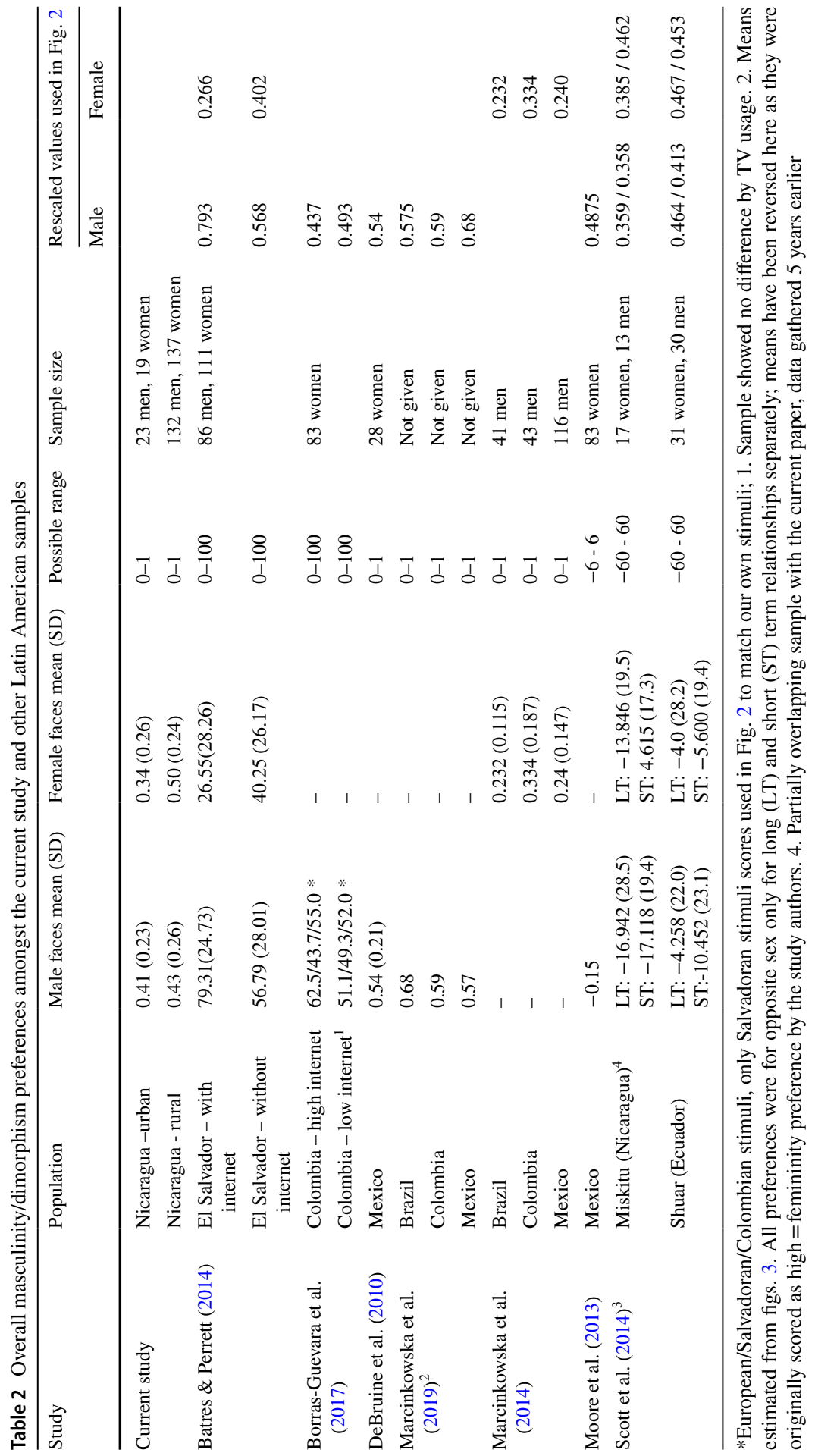




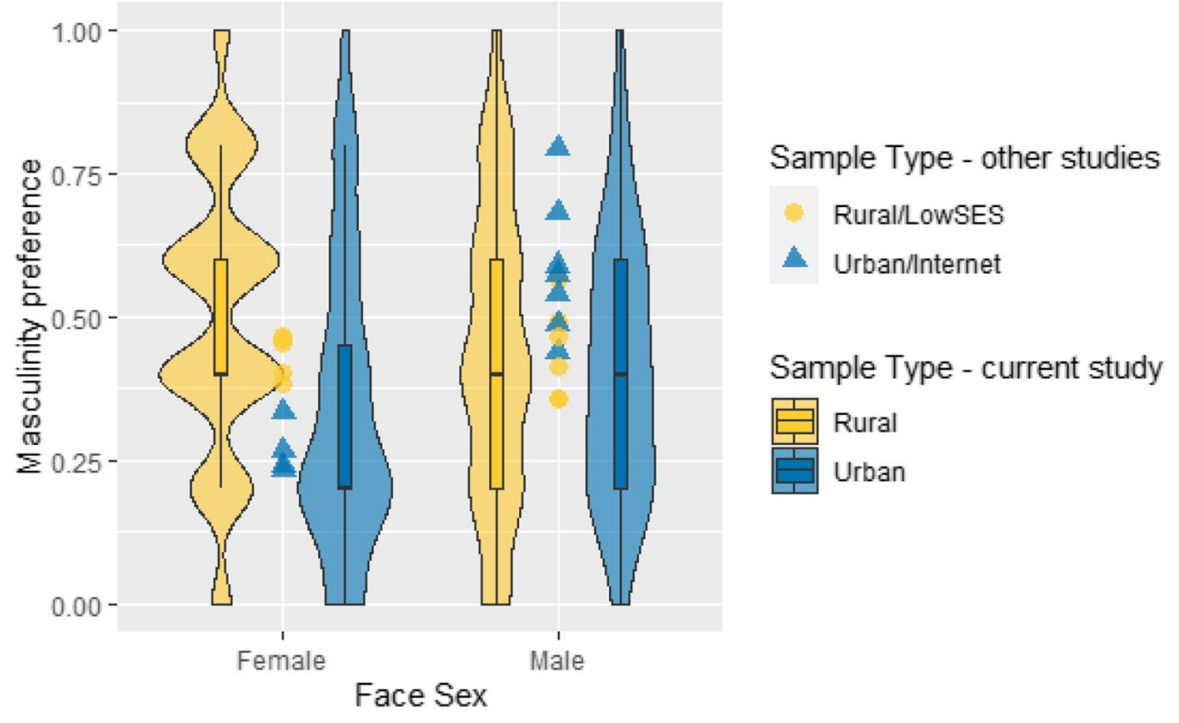

Fig. 2 Masculinity/dimorphism preferences in urban/internet participants vs rural/low SES participants in our own and others' Latin American research. Coloured points (circles and triangles) show mean preferences from other studies summarised in Table 2 , scaled to a $0-1$ range

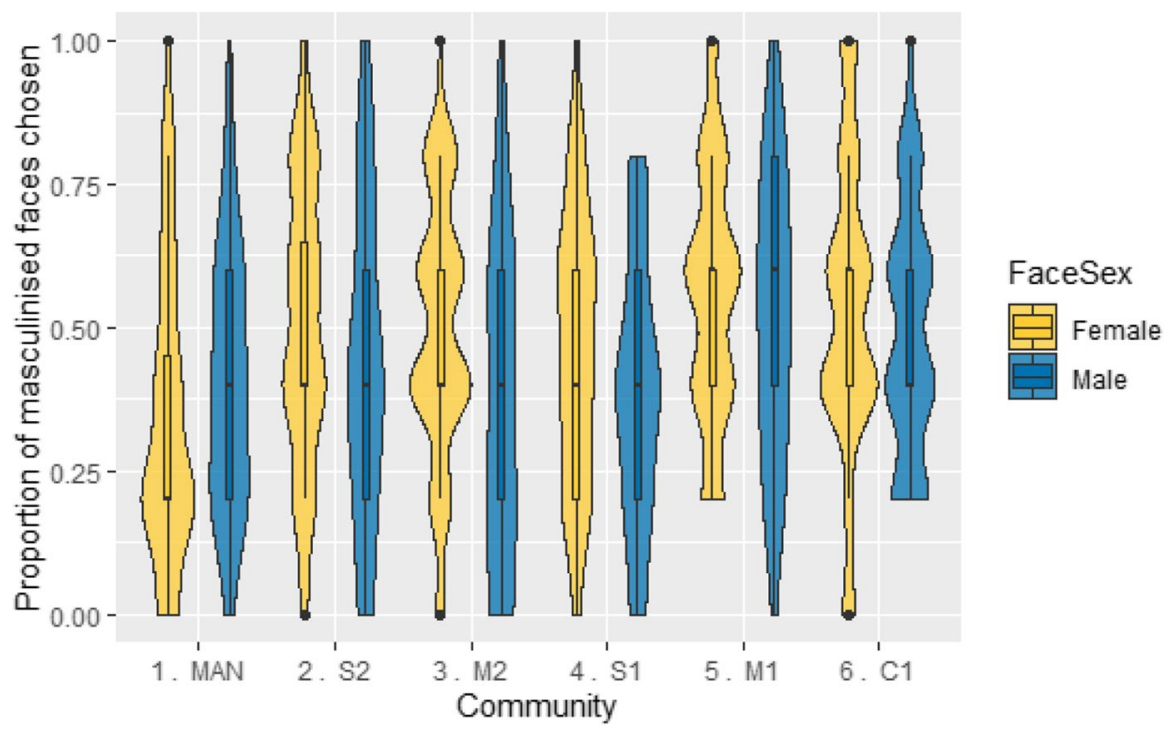

Fig. 3 Distribution and central tendency for dimorphism preferences in each location, ranked by development level from highest (capital city Managua) to lowest (village $\mathrm{C} 1$ ). (As a reminder on village codes, $\mathrm{S}=$ Spanish/Mestizo majority community, $\mathrm{M}=$ Miskitu majority community, $\mathrm{C}=$ Creole-speaking Garifuna majority community; $1=$ less television access, $2=$ more television access) 
Table 3 Zero order correlations between all predictors and face preferences

\begin{tabular}{lllllll}
\hline & & 1 & 2 & 3 & 4 & 5 \\
\hline 1 & Age & & & & & \\
2 & Income (US\$) & 0.11 & & & & \\
3 & Education (yrs) & $-.28^{* *}$ & $.13^{*}$ & & & \\
4 & TV (hrs) & $-.16^{* *}$ & 0.05 & $.44^{* *}$ & & \\
5 & Acculturation & 0.02 & $.16^{*}$ & 0 & $.16^{*}$ & \\
Masculinity preferences: & & & & & \\
6 & - male faces & -0.01 & 0.06 & -.11 & -0.07 & -0.05 \\
7 & - female faces & 0.05 & 0.08 & -0.08 & $-.15^{* *}$ & $-.21^{* *}$ \\
\hline
\end{tabular}

\begin{tabular}{llll}
\hline Predictors & $B$ & $S E$ & $p$ \\
\hline Ethnicity (mestizo) & 0.03 & 0.05 & 0.512 \\
Age & -0.00 & 0.00 & 0.483 \\
Observations & 133 & & \\
$\mathrm{R}^{2} / \mathrm{R}^{2}$ adjusted & $0.007 /-0.009$ & & \\
\hline
\end{tabular}

Table 4 Effect of ethnicity on women's preferences for male faces, in a linear regression model

sometimes no real preference. We note that across previous studies, masculinity preferences have tended to be higher in urban/internet samples, but there is some overlap with rural samples. For female faces, our rural participants showed no overall preference for femininity (which would have been indicated by a score significantly below .5), which is consistent with previous data from small scale societies or rural participants in this region, which have tended to show only small, or null preferences for femininity. Our urban participants showed a clear directional preference for femininity (see Hypothesis 4 below for inferential test), in common with other Latin American urban/internet based samples. Notably, there is no overlap in the means for urban/internet vs rural samples in prior research; urban/internet samples always showed stronger femininity preferences.

Zero order correlations between variables for the full sample (including the urban comparator group) are shown in Table 3 . Male facial masculinity preferences were associated at the whole-sample level with education, such that more years of education was linked to weaker masculinity preferences. Masculinity preference in female faces were negatively correlated with both TV consumption and acculturation, although as noted above acculturation mapped closely onto mestizo ethnicity and urbanisation.

Specific hypotheses will now be addressed in order. Key tests of each hypothesis have been tabulated, sometimes together (Tables 4, 5, and 6). Additional analyses can be found in the supplementary output file. Note, however, that all meanginful significant results are already included in the main text/tables. 
Table 5 Effects of age on women's preferences for male facial dimorphism. (Younger adult $=$ age $<20$; Older adult $=$ age $>45$ )

\begin{tabular}{|c|c|c|c|c|c|c|}
\hline Predictors & $B$ & $S E$ & $p$ & $B$ & $S E$ & $p$ \\
\hline Age & 0.01 & 0.01 & 0.486 & & & \\
\hline $\mathrm{Age}^{2}$ & 0.00 & 0.00 & 0.402 & & & \\
\hline Age group [older adult] & & & & -0.07 & 0.09 & 0.475 \\
\hline Age group [young adult] & & & & 0.03 & 0.05 & 0.566 \\
\hline \multicolumn{7}{|l|}{ Random Effects } \\
\hline$\sigma 2$ & 0.07 & & & 0.07 & & \\
\hline$\tau 00$ & 0.00 village & & & 0.00 village & & \\
\hline ICC & 0.01 & & & 0.01 & & \\
\hline $\mathrm{N}$ & 5 village & & & 5 village & & \\
\hline Observations & 133 & & & 133 & & \\
\hline Marginal / Conditional $\mathrm{R}^{2}$ & $0.008 / 0.018$ & & & $0.008 / 0.020$ & & \\
\hline
\end{tabular}

\section{Hypothesis 1: Ethnic Group Effects as a Proxy for Sociosexuality Norms}

There was no effect of ethnicity on women's facial masculinity preferences (Table 4), nor in further analyses for other combinations of observer gender and face sex.

\section{Hypothesis 2: Effects of Age}

There was no significant linear or quadratic effect of women's age on their preferences for facial masculinity in male faces, nor did women of different age groups differ from one another (see Table 5.) Follow up analyses (see supplementary output file, section 3.3.2) showed no age effects for women viewing women's faces, nor men viewing either sex of face.

\section{Hypothesis 3: Effects of Relationship Status}

There was no effect of relationship status on women's facial masculinity preferences (see Table 6). Additional analyses likewise showed no associations for male preferences, or women's preferences for female faces (see supplementary output file, section 3.4.2).

\section{Hypothesis 4: Effects of Urbanisation and Development}

Preferences for female faces were significantly different between urban and rural participants (see Table 7); urban participants preferred significantly more feminine/ less masculine female faces than other participants. There was no difference for male faces. Analyses concentrating on relative (rank) size and development of villages showed no linear effect of village rank on facial preferences between villages 


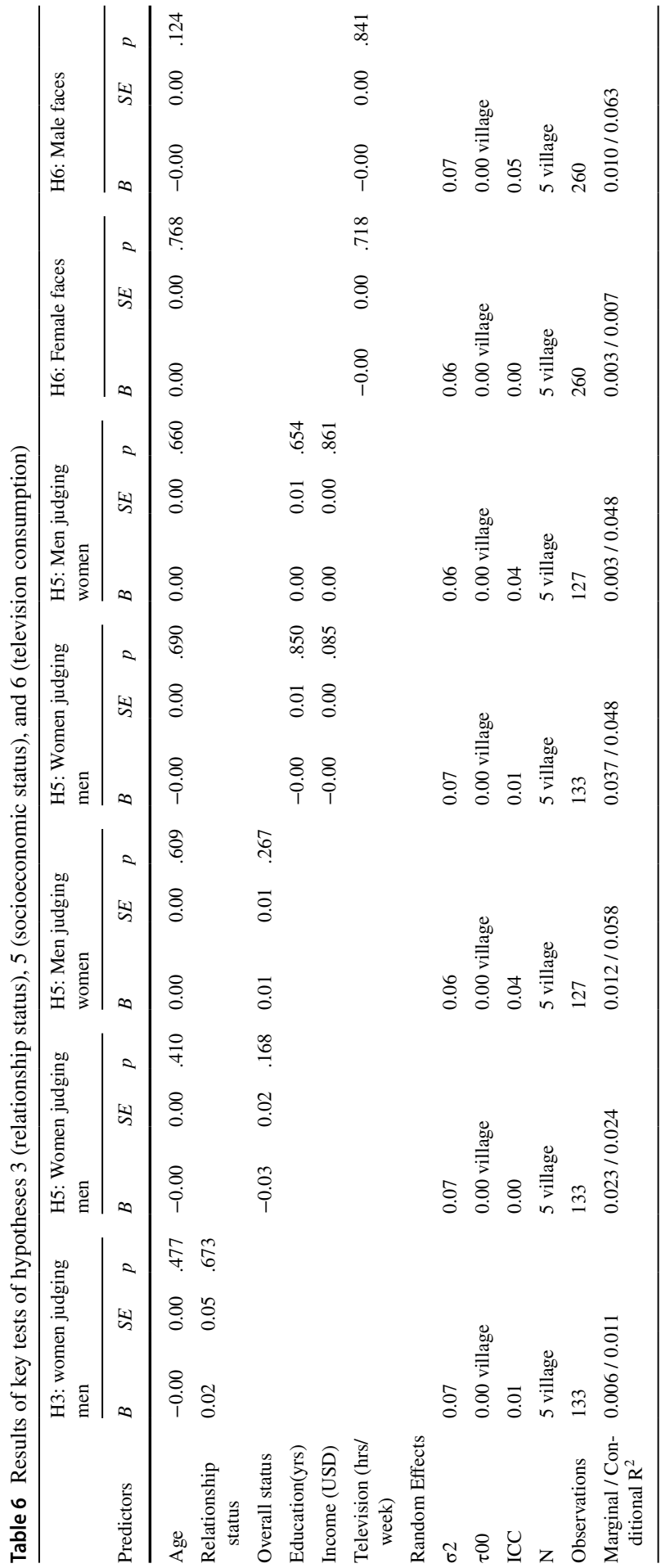




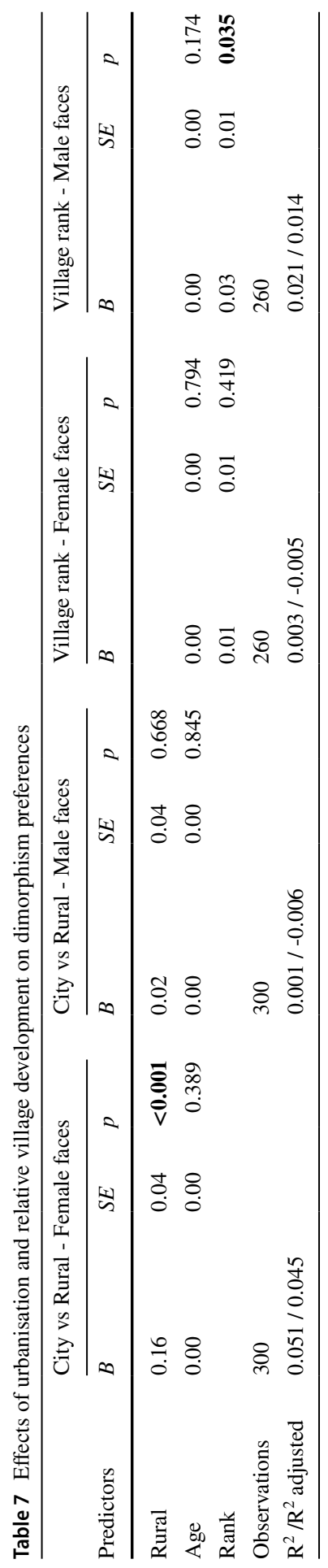


for female faces. There was a significant linear effect for male faces such that less developed villages had stronger masculinity preferences, i.e. the opposite to our prediction. However, further analyses using spline models (to account for the ordinal nature of the data) showed that a 4-spline model had slightly better fit than a linear model for male facial preferences (see supplementary output file, section 3.5.2) although only one of the terms within that model was significant. Further examining the data by comparing all villages against the smallest village $\mathrm{C} 1$ in a linear model with village as a categorical predictor, showed that village M2 (the second most developed village) had significantly weaker preferences than $\mathrm{C} 1$ ( $B=-.119$, $S E=.055, p=.030$; see supplementary output file, section 3.5.3). As shown in Fig. 2, there was no other clear evidence to support the hypothesis that development at the village level was associated with increased dimorphism preference.

\section{Hypothesis 5: Effects of Education and Income}

As shown in Table 6, there was no association between status (education and income combined or separately) and men's or women's preferences for opposite sex faces. There were no significant 3-way interaction effects for status by participant sex by face sex (see Supplementary output file, section 3.6.2).

\section{Hypothesis 6: Effects of Television Consumption}

Although there was a significant association between television consumption and preferences for female faces in the initial correlations of the full sample above, this was not significant for the rural sample when the data were analysed in a mixed effect model to account for clustering (Table 6.) There was also no association between television consumption and preferences for male faces.

\section{Qualitative Feedback from Local Residents}

Following completion of analyses, we shared examples of the stimuli and a brief summary of how they were made with seven local informants, and explained that while there are strong preferences for the female stimuli in the UK, we found no strong preferences amongst participants in their region. Informants were a mixture of Garifuna, Miskitu and Creole and lived in 3 different communities; as with our participants above, they differed in which faces they thought were more attractive with no particular agreement between them. They struggled to articulate what differences existed between the faces in each pair; some were unable to see any difference at all. Two informants claimed to prefer the faces which seemed to be smiling more, while two believed the masculinised female faces looked more 'clear', meaning White. All Miskitu informants were able to discuss features they like in faces, but none of these aligned with sexual dimorphism. The Garifuna informants generally emphasised character and/or body shape and movement (see also Thornborrow et al., 2018). In general these responses aligned with observations made during 
testing, where participants were able to make a choice between faces but often observed to JLJ or TT that they couldn't see the difference.

\section{Discussion}

This paper sought to test previously established patterns in facial dimorphism preferences amongst a sample of rural Nicaraguans undergoing technological development, and an urbanised comparison group. Results for all hypotheses are summarised in Table 8. In short, none of our hypotheses derived from sexual selection were supported; women from ethnic groups with stronger norms against unrestricted sociosexuality did not show weaker masculinity preferences, women's masculinity preferences did not 'peak' during the reproductive years, and women in committed (cohabiting) relationships did not differ from other women in their preferences. Furthermore, not only were there no other effects in other participant/face gender combinations, but our rural participants did not even show a preference for feminised female faces, despite this being a strongly consistent preference across samples from the internet and/or populations with high development indices.

Our hypotheses based on economic development fared only a little better. Urban participants did show a preference for feminised female faces, in common with other urban/internet samples in Latin America and beyond. However, there was no clear evidence amongst our rural participants that those living in larger and more 'developed' communities showed more 'globalised' face preferences; although two villages differed on male masculinity preferences this difference was in the opposite direction to our prediction and was not reflected in the rest of the villages. There was also no evidence for an effect of other aspects of acculturation, namely education, income or television consumption, once the structure of the data was taken into account in multi-level models.

While the null results regarding education and television consumption may be surprising given the strong evidence for media consumption affecting other aspects of attraction in this population (female body size and shape; see Boothroyd et al., 2020; Jucker et al., 2017; Thornborrow et al., 2018), other work using the same stimuli in another Latin American population found effects of internet-access but not television consumption (Borras-Guevara et al., 2017; see also Batres \& Perrett, 2014, who found internet effects using European stimuli). Given that most of the television content our participants viewed consisted of British and American films, Mexican and Colombian soap operas, and sports, news, and reality police shows which in combination predominantly show White and Mestizo faces, one cannot argue that the faces seen in media are typical of those in the local population, which includes high levels of ethnic diversity. It may be, however, that the levels of dimorphism on television are not atypical, although we do not have sufficient data on our participants' faces to test this.

Perhaps more likely, is that amongst our rural participants, facial shape dimorphism may not be a generally salient feature of attractiveness - at least within the range we tested, which ran from androgynous to exaggerated masculinity/femininity for male and female faces respectively. As noted above, informants we discussed 


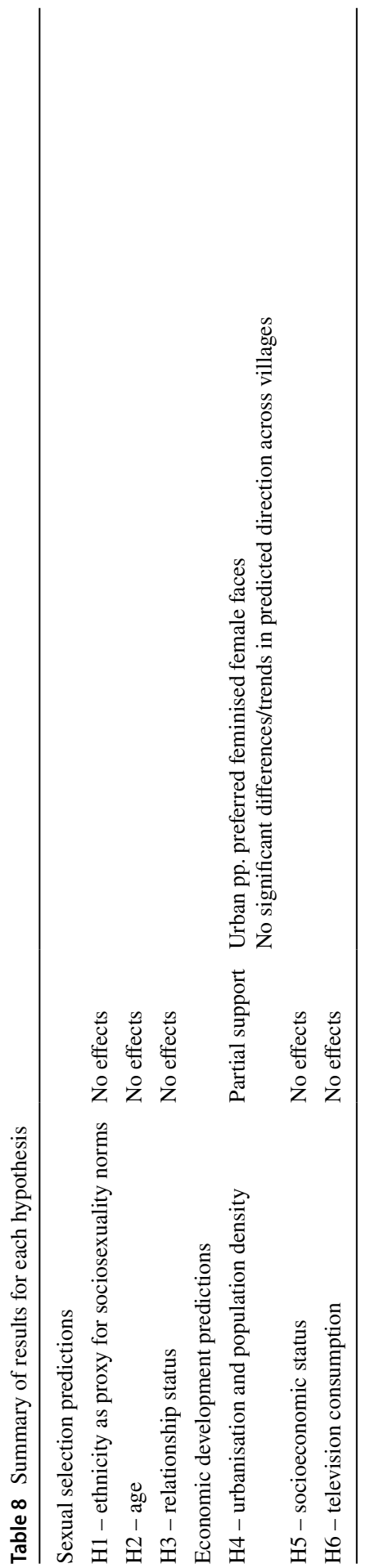


our stimuli and results with struggled to register the differences in the stimuli and instead suggested other facial features they found more important. During focus group discussions with men in partially overlapping communities, Thornborrow et al. (2018) found that men tended to focus on the movement and body shape of potential sexual partners, and on the personality/temperament of a potential wife. They did not mention faces at all. And thus, while the urban participants may have displayed more 'typical' preferences for feminine female faces, rural participants may not have necessarily attended to this in their general social interactions or in the media they consumed. This parallels the data of Scott et al. (2014) who found no clear femininity preferences in several of their 'small scale' populations with low or zero market integration. Even the largest of our villages may not have been large or dense enough to result in the preferences consistently found in fully urban populations.

If facial dimorphism is of such low salience in these populations, this raises the question of whether it would have been salient in ancestral populations, as well as what other 'typical' features of attraction may be absent in these samples. Indeed, Scott et al. (2014) already suggested that preferences for greater than average facial dimorphism may be 'evolutionarily novel'. Our data are therefore an important contribution to the burgeoning literature questioning the importance previously placed on facial dimorphism in attraction research, and further questioning the validity of supposed instances of sexually selected preferences.

We previously noted that our sample was under-powered for some analyses and furthermore, our test of the sociosexuality hypothesis was via an ethnic proxy rather than direct. Furthermore, we did not assess relationship commitment, and so cannot exactly duplicate previous studies on relationship status. However, the combination of a lack of femininity preference in female faces, and a lack of age effects despite these being seen quite strongly in published work in the UK, suggests that low power cannot explain our full roster of null results. Similarly, while we used Latin American facial stimuli rather than the White faces more typically used in these studies, those stimuli showed similar patterns to European faces in a Colombian sample (Borras-Guevara et al., 2017), and are appropriate for the cultural context in question. We would therefore consider it unlikely that an adapted preference would not be found using these stimuli in this population.

We strongly urge other researchers to test existing patterns of mate choice in more diverse, less studied populations, as an essential step in further establishing the extent of 'universality' in systematic mate choice variation.

Supplementary Information The online version contains supplementary material available at https://doi. org/10.1007/s40750-021-00173-5.

Acknowledgements The authors thank our hosts and participants in Nicaragua, and the reviewers and editor at both Stage 1 and Stage 2 submission of this manuscript for their helpful and supportive comments.

Funding Data collection was funded by a Leverhulme Trust grant to LGB and MJT (RPG-2013-113).

Data Availability To prevent participant re-identification, redacted and simulated data are included as a supplement to the published paper. 


\section{Declarations}

Conflict of Interest On behalf of all authors, the corresponding author states that there is no conflict of interest.

Open Access This article is licensed under a Creative Commons Attribution 4.0 International License, which permits use, sharing, adaptation, distribution and reproduction in any medium or format, as long as you give appropriate credit to the original author(s) and the source, provide a link to the Creative Commons licence, and indicate if changes were made. The images or other third party material in this article are included in the article's Creative Commons licence, unless indicated otherwise in a credit line to the material. If material is not included in the article's Creative Commons licence and your intended use is not permitted by statutory regulation or exceeds the permitted use, you will need to obtain permission directly from the copyright holder. To view a copy of this licence, visit http://creativecommons.org/licen ses/by/4.0/.

\section{References}

Allaire, J.J., Xie, Y., McPherson, J., Luraschi, J., Ushey, K., Atkins, A., Wickham, H., Cheng, J., Chang, W. \& Iannone, R. (2020). Rmarkdown: Dynamic documents for R. R package version 2.4. https:// www.rmarkdown.rstudio.com.

Bates, D., Maechler, M., Bolker, B., \& Walker, S. (2015). Fitting linear mixed-effects models using lme4. Journal of Statistical Software, 67(1), 1-48. https://doi.org/10.18637/jss.v067.i01.

Batres, C., \& Perrett, D. I. (2014). The influence of the digital divide on face preferences in El Salvador: People without internet access prefer more feminine men, more masculine women, and women with higher adiposity. PLoS One, 9(7), e100966.

Batres, C., Kannan, M., \& Perrett, D. I. (2017). Familiarity with own population's appearance influences facial preferences. Human Nature, 28(3), 344-354.

Booth, A., \& Dabbs Jr., J. M. (1993). Testosterone and men's marriages. Social Forces, 72(2), $463-477$.

Boothroyd, L. G., Jones, B. C., Burt, D. M., DeBruine, L. M. \& Perrett, D. I. (2008). Facial correlates of sociosexuality. Evolution \& Human Behavior, 29(3), 211-218.

Boothroyd, L. G., Lawson, J. F., \& Michael Burt, D. (2009). Testing immunocompetence explanations of male facial masculinity. Journal of Evolutionary Psychology, 7(1), 65-81.

Boothroyd, L. G., Cross, C. P., Gray, A. W., Coombes, C. \& Gregson-Curtis, K. (2011). Perceiving the facial correlates of sociosexuality: Further evidence. Personality and Individual Differences, 50(3), $422-425$.

Boothroyd, L. G., Scott, I., Gray, A. W., Coombes, C. I., \& Pound, N. (2013). Male facial masculinity as a cue to health outcomes. Evolutionary Psychology, 11(5), 147470491301100508.

Boothroyd, L. G., \& Brewer, G. (2014). Self-reported impulsivity, rather than sociosexuality, predicts women's preferences for masculine features in male faces. Archives of Sexual Behavior, 43(5), 983-988.

Boothroyd, L. G., Meins, E., Vukovic, J., \& Burt, D. M. (2014). Developmental changes in children's facial preferences. Evolution and Human Behavior, 35(5), 376-383.

Boothroyd, L. G., Jucker, J. L., Thornborrow, T., Jamieson, M. A., Burt, D. M., Barton, R. A., Evans, E. H. \& Tovée, M. J. (2016). Television exposure predicts body size ideals in rural Nicaragua. British Journal of Psychology, 107(4), 752-767.

Boothroyd, L. G., Gray, A. W., Headland, T. N., Uehara, R. T., Waynforth, D., Burt, D. M., \& Pound, N. (2017). Male facial appearance and offspring mortality in two traditional societies. PLoS One, 12(1), e0169181.

Boothroyd, L. G. \& Vukovic, J. (2019). Mate Preferences Across the Lifespan. In Welling, L. M. \& Shackelford, T. K. (Eds) The Oxford Handbook of Evolutionary Psychology and Behavioral Endocrinology. Oxford University Press. 143-159.

Boothroyd, L. G., Jucker, J. L., Thornborrow, T., Barton, R. A., Burt, D. M., Evans, E. H., et al. (2020). Television consumption drives perceptions of female body attractiveness in a population undergoing technological transition. Journal of Personality and Social Psychology, 119(4), 839-860. 
Borras-Guevara, M. L., Batres, C., \& Perrett, D. I. (2017). Aggressor or protector? Experiences and perceptions of violence predict preferences for masculinity. Evolution and Human Behavior, 38(4), 481-489.

Brooks, R., Scott, I. M., Maklakov, A. A., Kasumovic, M. M., Clark, A. P., \& Penton-Voak, I. S. (2010). National income inequality predicts women's preferences for masculinized faces better than health does. Proceedings of the Royal Society B: Biological Sciences, 278(1707), 810-812.

Buss, D. M. (1988). The evolution of human intrasexual competition: Tactics of mate attraction. Journal of Personality and Social Psychology, 54(4), 616.

Cuellar, I., Harris, L. C., \& Jasso, R. (1980). An acculturation scale for Mexican American normal and clinical populations. Hispanic Journal of Behavioral Sciences.

Dabbs, J. M., Jurkovic, G. J., \& Frady, R. L. (1991). Salivary testosterone and cortisol among late adolescent male offenders. Journal of Abnormal Child Psychology, 19(4), 469-478.

DeBruine, L. M., Jones, B. C., Crawford, J. R., Welling, L. L., \& Little, A. C. (2010). The health of a nation predicts their mate preferences: Cross-cultural variation in women's preferences for masculinized male faces. Proceedings of the Royal Society B: Biological Sciences, 277(1692), 2405-2410.

Feinberg, D. R., Jones, B. C., DeBruine, L. M., Moore, F. R., Smith, M. J. L., Cornwell, R. E., Tiddemanm B, P, Boothroyd, L.G., \& Perrett, D. I. (2005). The voice and face of woman: One ornament that signals quality? Evolution and Human Behavior, 26(5), 398-408.

Holzleitner, I. J., \& Perrett, D. I. (2017). Women's preferences for men's facial masculinity: Trade-off accounts revisited. Adaptive Human Behavior and Physiology, 3(4), 304-320.

Jamieson, M. (2018). Cocaine money, cement houses, and new residential arrangements in a coastal Miskitu village. In L. Baracco (Ed.), Indigenous struggles for autonomy. Lexington Books.

Jones, B. C., Vukovic, J., Little, A. C., Roberts, S. C., \& DeBruine, L. M. (2011). Circum-menopausal changes in women's preferences for sexually dimorphic shape cues in peer-aged faces. Biological Psychology, 87(3), 453-455.

Jones, B. C., Hahn, A. C., Fisher, C. I., Wang, H., Kandrik, M., Han, C., et al. (2018a). No compelling evidence that preferences for facial masculinity track changes in women's hormonal status. Psychological Science, 29(6), 996-1005.

Jones, B. C., Hahn, A. C., Fisher, C. I., Wang, H., Kandrik, M., Lao, J., et al. (2018b). No compelling evidence that more physically attractive young adult women have higher estradiol or progesterone. Psychoneuroendocrinology, 98, 1-5.

Jucker, J. L., Thornborrow, T., Beierholm, U., Burt, D. M., Barton, R. A., Evans, E. H., et al. (2017). Nutritional status and the influence of TV consumption on female body size ideals in populations recently exposed to the media. Scientific Reports, 7(1), 1-9.

Jünger, J., Kordsmeyer, T. L., Gerlach, T. M., \& Penke, L. (2018). Fertile women evaluate male bodies as more attractive, regardless of masculinity. Evolution and Human Behavior, 39(4), 412-423.

Kordsmeyer, T. L., Lohöfener, M., \& Penke, L. (2019). Male facial attractiveness, dominance, and health and the interaction between cortisol and testosterone. Adaptive Human Behavior and Physiology, 5(1), 1-12.

Law Smith, M. J., Perrett, D. I., Jones, B. C., Cornwell, R. E., Moore, F. R., Feinberg, D. R., et al. (2005). Facial appearance is a cue to oestrogen levels in women. Proceedings of the Royal Society B: Biological Sciences, 273(1583), 135-140.

Little, A. C., Jones, B. C., Penton-Voak, I. S., Burt, D. M., \& Perrett, D. I. (2002). Partnership status and the temporal context of relationships influence human female preferences for sexual dimorphism in male face shape. Proceedings of the Royal Society of London. Series B: Biological Sciences, 269(1496), 1095-1100.

Little, A. C., Saxton, T. K., Roberts, S. C., Jones, B. C., DeBruine, L. M., Vukovic, J., et al. (2010). Women's preferences for masculinity in male faces are highest during reproductive age range and lower around puberty and post-menopause. Psychoneuroendocrinology, 35(6), 912-920.

Lüdecke D (2020). sjPlot: Data visualization for statistics in social Science. R package version 2.8.6. URL: https://CRAN.R-project.org/package=sjPlot.

Marcinkowska, U. M., Kozlov, M. V., Cai, H., Contreras-Garduño, J., Dixson, B. J., Oana, G. A., ... \& Rantala, M. J. (2014). Cross-cultural variation in men's preference for sexual dimorphism in women's faces. Biology Letters, 10(4), 20130850.

Marcinkowska, U. M., Galbarczyk, A., \& Jasienska, G. (2018). La donna è mobile? Lack of cyclical shifts in facial symmetry, and facial and body masculinity preferences-A hormone based study. Psychoneuroendocrinology, 88, 47-53. 
Marcinkowska, U. M., Rantala, M. J., Lee, A. J., Kozlov, M. V., Aavik, T., Cai, H., et al. (2019). Women's preferences for men's facial masculinity are strongest under favorable ecological conditions. Scientific Reports, 9(1), 1-10.

Moore, F. R., Cassidy, C., Smith, M. J. L., \& Perrett, D. I. (2006). The effects of female control of resources on sex-differentiated mate preferences. Evolution and Human Behavior, 27(3), 193-205.

Moore, F., Cassidy, C., \& Perrett, D. I. (2010). The effects of control of resources on magnitudes of sex differences in human mate preferences. Evolutionary Psychology, 8(4), 147470491000800412.

Moore, F. R., Coetzee, V., Contreras-Garduño, J., DeBruine, L. M., Kleisner, K., Krams, I., et al. (2013). Cross-cultural variation in women's preferences for cues to sex-and stress-hormones in the male face. Biology Letters, 9(3), 20130050.

Penton-Voak, I. S., Perrett, D. I., Castles, D. L., Kobayashi, T., Burt, D. M., Murray, L. K., \& Minamisawa, R. (1999). Menstrual cycle alters face preference. Nature, 399, 741-742.

Penton-Voak, I. S., Jacobson, A., \& Trivers, R. (2004). Populational differences in attractiveness judgements of male and female faces: Comparing British and Jamaican samples. Evolution and Human Behavior, 25(6), 355-370.

Perrett, D. I., Lee, K. J., Penton-Voak, I., Rowland, D., Yoshikawa, S., Burt, D. M., et al. (1998). Effects of sexual dimorphism on facial attractiveness. Nature, 394(6696), 884.

R Core Team (2020). R: A language and environment for statistical computing. R Foundation for statistical computing, Vienna. https://www.R-project.org/.

Rhodes, G., Hickford, C., \& Jeffery, L. (2000). Sex-typicality and attractiveness: Are supermale and superfemale faces super-attractive? British Journal of Psychology, 91(1), 125-140.

Rhodes, G., Chan, J., Zebrowitz, L. A., \& Simmons, L. W. (2003). Does sexual dimorphism in human faces signal health? Proceedings of the Royal Society of London. Series B: Biological Sciences, 270(suppl_1), S93-S95.

RStudio Team. (2020). RStudio: Integrated development for R. RStudio http://www.rstudio.com/.

Saxton, T. K., DeBruine, L. M., Jones, B. C., Little, A. C., \& Craig Roberts, S. (2011). A longitudinal study of adolescents' judgments of the attractiveness of facial symmetry, averageness and sexual dimorphism. Journal of Evolutionary Psychology, 9(1), 43-55.

Scott, I., Swami, V., Josephson, S. C., \& Penton-Voak, I. S. (2008). Context-dependent preferences for facial dimorphism in a rural Malaysian population. Evolution and Human Behavior, 29(4), 289-296.

Scott, I. M., Clark, A. P., Josephson, S. C., Boyette, A. H., Cuthill, I. C., Fried, R. L., et al. (2014). Human preferences for sexually dimorphic faces may be evolutionarily novel. Proceedings of the National Academy of Sciences, 111(40), 14388-14393.

Stanley, D. (2021). apaTables: Create American Psychological Association (APA) style tables. R package version 2.0.8. https://CRAN.R-project.org/package=apaTables

Suinn, R. M., Rickard-Figueroa, K., Lew, S., \& Vigil, P. (1987). The Suinn-Lew Asian self-identity acculturation scale: An initial report. Educational and Psychological Measurement, 47(2), 401-407.

Thornborrow, T., Jucker, J. L., Boothroyd, L. G., \& Tovée, M. J. (2018). Investigating the link between television viewing and men's preferences for female body size and shape in rural Nicaragua. Evolution and Human Behavior, 39(5), 538-546.

Thornborrow, T., Onwuegbusi, T., Mohamed, S., Boothroyd, L. G., \& Tovée, M. J. (2020). Muscles and the media: A natural experiment across cultures in Men's body image. Frontiers in Psychology, 11, 495.

Thornhill, R., \& Gangestad, S. W. (1999). Facial attractiveness. Trends in Cognitive Sciences, 3(12), 452-460.

Vukovic, J., Jones, B. C., DeBruine, L. M., Little, A. C., Feinberg, D. R., \& Welling, L. L. (2008). Circum-menopausal effects on women's judgements of facial attractiveness. Biology Letters, 5(1), 62-64.

Waynforth, D., Delwadia, S., \& Camm, M. (2005). The influence of women's mating strategies on preference for masculine facial architecture. Evolution and Human Behavior, 26, 409-416.

Wickham, H. (2016). ggplot2: Elegant graphics for data analysis. Springer-Verlag.

Zaidi, A. A., White, J. D., Mattern, B. C., Liebowitz, C. R., Puts, D. A., Claes, P., \& Shriver, M. D. (2019). Facial masculinity does not appear to be a condition-dependent male ornament and does not reflect MHC heterozygosity in humans. Proceedings of the National Academy of Sciences, 116(5), 1633-1638. 
Publisher's Note Springer Nature remains neutral with regard to jurisdictional claims in published maps and institutional affiliations.

\section{Authors and Affiliations}

\section{Lynda G. Boothroyd ${ }^{1}$ (1) . Jean-Luc Jucker ${ }^{1}$. Tracey Thornborrow ${ }^{2}$.} Martin J. Tovee $^{3} \cdot$ Carlota Batres ${ }^{4} \cdot$ Ian Penton-Voak ${ }^{5}$

$\triangle$ Lynda G. Boothroyd

L.G.Boothroyd@dur.ac.uk

1 Department of Psychology, Durham University, South Road, Durham DH1 3LE, UK

2 School of Psychology, University of Lincoln, Brayford Pool, Lincoln, Lincolnshire LN6 7TS, UK

3 Department of Psychology; Faculty of Health and Life Sciences, Northumbria University, Newcastle upon Tyne NE1 8ST, UK

4 Department of Psychology, Franklin and Marshall College, Lancaster, PA 17604-3003, USA

5 School of Psychological Science, University of Bristol, 12a Priory Road, Bristol BS8 1TU, UK 